\title{
Cotoneaster acuminatus Leaf Extract Mediated Synthesis, Characterization and In vitro Evaluation of Antimicrobial Activity of Zinc Oxide Nanoparticles
}

\section{GOUTAM KUMAR ${ }^{1}$, P. P. BADONI ${ }^{1}$, ARUN K. KHAJURIA ${ }^{2}$, MAHENDER SINGH ${ }^{1}$, SAPNA TYAGI ${ }^{3}$ and NAVNEET SINGH ${ }^{4 *}$}

\author{
'Department of Chemistry, Hemvati Nandan Bahuguna Garhwal University, Pauri Garhwal-246001, \\ Uttarakhand, India. \\ 2Department of Botany, Cluster University of Jammu, Jammu-184001, Jammu and Kashmir, India. \\ ${ }^{3}$ Department of Chemistry, K.L.D.A.V. (P.G.) College,Roorkee- 247667, Uttarakhand, India. \\ ${ }^{4}$ Department of Applied Science and Humanities, Roorkee College of Engineering, \\ Roorkee-247667, Uttarakhand, India. \\ *Corresponding author E-mail: navneets176@gmail.com \\ http://dx.doi.org/10.13005/ojc/360606
}

(Received: September 28, 2020; Accepted: November 13, 2020)

\begin{abstract}
In recent years, there is significant increase in the attention towards the green synthesis of metal oxide nanoparticles, particularly by the interaction of plant extracts and metal salts; still there is no such published evidence is available on the synthesis of $\mathrm{ZnO}$ nanoparticles from aqueous leaf extract of Cotoneaster acuminatus. The synthesis of $\mathrm{ZnO}$ nanoparticles was confirmed by using several spectroscopic techniques i.e., UV-Vis, FT-IR, powder-XRD and TEM. It was confirmed from the spectroscopic data that the synthesized nanoparticles were hexagonally orientated, size in the 16-38 nm range and encapsulated by biochemicals present in the leaf extract. These nanoparticles were further evaluated for antimicrobial activity Bacillus subtilis NCFT.583.08, Staphylococcus aureus NCFT.576.08, Pseudomonas aeruginosa NCFT.645.11, Candida albicans NCFT.1006.11 and Saccharomyces cerevisiae NCFT.1008.11 strains. This research work might be considered as a successful attempt to create and evaluate medicinal properties of $\mathrm{ZnO}$ nanoparticles in combination with Cotoneaster acuminatus leaf extract.
\end{abstract}

Keywords: ZnO nanoparticles, Cotoneaster acuminatus, Encapsulated, Antimicrobial activity.

\section{INTRODUCTION}

Metallic nanoparticles are of great importance because of their advanced physicochemical and biological activities over their bulk phase. The nanoparticle having size less than $100 \mathrm{~nm}$ shows a higher surface to volume ratio which led to elevated surface activity. This unique property allowed them to be exploited in vast applications in many tasks of nano-biotechnology. Nano-biotechnology is the combination of nanotechnology and biotechnology for developing bio inspired and environmental skill

This is an Open Access article licensed under a Creative Commons license: Attribution 4.0 International (CC- BY). Published by Oriental Scientific Publishing Company @ 2018

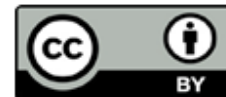


for the synthesis of nanoparticles ${ }^{1,2}$. Previously green synthesis of $\mathrm{ZnO}$ nanoparticles using plant extracts have been reported using numerous medicinal plants which includes the extract of Camellia sinesis ${ }^{3}$, Calotropis procera ${ }^{4}$, Hybanthus enneaspermus ${ }^{5}$, Mimosa pudica ${ }^{6}$, Micrococca $^{4}$ mercurialis ${ }^{7}$, Naphelium lappaceum ${ }^{8}$, Nyctanthes arbor-tristis ${ }^{9}$ etc. by different researchers and these studies indicated the presence of biochemicals such as amines, aldehydes, phenols etc. for stabilizing the metallic forms ${ }^{10}$.

ZnO nanoparticles have noteworthy medicinal properties in the field of medication. Excellent bactericidal properties of these nanoparticles against microorganisms have been reported $^{11,12}$. In different field of therapeutics like antioxidant, antidiabetic, anticancer and parasitic activities of zinc oxide nanoparticles also reported in literature ${ }^{13,14}$. $\mathrm{ZnO}$ nanoparticles are nontoxic, biocompatible and biosafe ${ }^{15}$ and due to its skin compatible properties it is widely used in sunscreens materials ${ }^{16}$. The benefit of using metal oxides such as $\mathrm{ZnO}$ as antimicrobial nano-agents is that they include mineral nutrient essential to humans and demonstrate strong action even when administered in very small amounts. These nanoparticles show powerful antibacterial activities against various bacteria as reviewed ${ }^{17}$. In present work, leaves of Cotoneaster acuminatus were used for the bio-fabrication of zinc oxides nanoparticles. It is a deciduous shrub having height upto $4 \mathrm{~m}$; with ovatelanceolated leaves, base rounded, tip acuminated with flat margins and rich in medicinal properties ${ }^{18}$. Chemicals presents in leaves of $C$. acuminatus are helpful in the reduction and stabilization of synthesized $\mathrm{ZnO}$ nanoparticles and it was predicted from already reported study that involved synthesis of silver nanoparticles ${ }^{19}$. A study reported the antimicrobial activity of its alcoholic root extract and also assisted in investigating the biochemicals present in its extract like glucopyranoside and rhamnopyranoside along with known compounds such as glucoside, phenolic glycoside, apigenin and epicatechin ${ }^{20}$. The evaluation motive of antimicrobial properties of $\mathrm{ZnO}$ nanoparticles synthesized using C. acuminatus leaf extract on nanoscale was to explore their improvised medicinal properties.

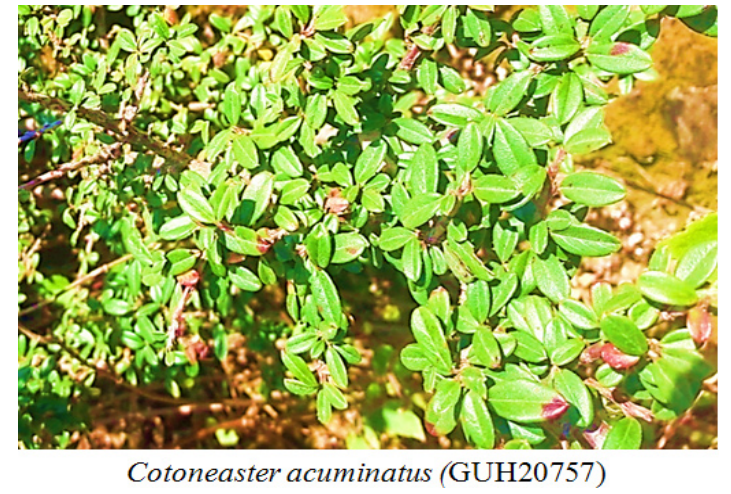

MATERIALS AND METHODS

\section{Chemical and reagents}

Analytical grade of zinc acetate dihydrate $\left(\mathrm{Zn}(\mathrm{OAc})_{2} \cdot 2 \mathrm{H}_{2} \mathrm{O}\right)$ and sodium hydroxide $(\mathrm{NaOH})$ were used for research work from Sigma-Aldrich. Experimental works were performed by using deionized distilled water.

\section{Culture Media}

Soyabean casein digest and Sabouraud's dextrose broth of Hi Media Pvt. Bombay, India were used for antibacterial and antifungal test, respectively. Pure cultures of bacterial strains, viz. Bacillus subtilis (NCFT.583.08), Staphylococcus aureus (NCFT.576.08), Pseudomonas aeruginosa (NCFT.645.11) and Fungal strains, Candida albicans (NCFT.1006.11) and Saccharomyces cerevisiae (NCFT.1008.11) were used for the evaluation of antimicrobial activity.

\section{Plant Collection and Preparation of Plant Extract}

Cotoneaster acuminatus plant specimen was collected from Nag Dev Hills, Pauri (Garhwal), India and authenticated from HNB Garhwal University Herbarium under its voucher specimens no. GUH20757. C. acuminatus leaves were collected and washed several times with deionized-distilled water to remove any of the adhering dust particles and subsequently incised into very small pieces, placed in a hot air oven at $35^{\circ} \mathrm{C}$ and then meshed to the powder form using mortar-pestle. In a $250 \mathrm{~mL}$ Erlenmeyer conical flask, $0.5 \mathrm{~g}$ of dried and finely cut C. acuminatus leaves and $100 \mathrm{~mL}$ deionized distilled water were heated for $25 \mathrm{~min}$ at $70^{\circ} \mathrm{C}$. After cooling, leaf extract was filtered in a separate conical flask and stored for further research work. 


\section{Zinc oxide nanoparticles (ZnO Nps) synthesis}

$50 \mathrm{~mL}$ of Cotoneaster acuminatus leaf extract was taken in a $250 \mathrm{~mL}$ of Erlenmeyer conical flask. It was heated on magnetic stirrer at $70^{\circ} \mathrm{C}$ for 10 minutes. Then $100 \mathrm{~mL}$ of $100 \mathrm{mM}$ Zinc acetate dihydrate solution was added drop by drop to it, keeping temperature constant at $70^{\circ} \mathrm{C}$ along with adjusting $\mathrm{pH}$ range within 08-10 of the solution by adding few drops of $1 \mathrm{M} \mathrm{NaOH}$ solution. Color change of the solution was observed from light yellow to reddish brown. Reaction conditions were maintained for $30 \mathrm{~min}$ and then cooled at room temperature. Consequently, the cooled solution was centrifuged at $5000 \mathrm{rpm}$ for 10 minutes. To remove unreacted and uncoordinated material, collected $\mathrm{ZnO}$ nanoparticles were centrifuged again for several times with water and ethanol. ZnO nano-powder was collected by drying in the oven at $50^{\circ} \mathrm{C}$.

\section{Determination of Antimicrobial Activity}

The methodology used for determining the diameter of zone of inhibition, minimum inhibitory and lethal concentration is according to the references ${ }^{21-}$ ${ }^{23}$ with some modifications. Soyabean casein digest broth was used to inoculate into selected bacteria at $37^{\circ} \mathrm{C}$ for $18 \mathrm{~h}$ and further suspension was ensured to provide approximately, $108 \mathrm{CFU} / \mathrm{mL}$. The similar steps were employed for fungal strains but in this case Sabouraud's dextrose broth was exercised for inoculation at 48-72 hours. Bacterial culture in Soyabean Casein Digest medium (SCDM) medium was inoculated and separately suspended in broth. $8 \mathrm{~mm}$ diameter wells were punched into agar and loaded with nan-solution (in DMSO) and solvent blanks. Erythromycin, (1 mg/mL) was concurrently employed as the positive control and DMSO as negative control. Subsequently the plates were incubated at $37^{\circ} \mathrm{C}$ for 18 horus. The antibacterial activity was determined by quantifying the diameter of zone of inhibition. For assaying, antifungal property of nano-solution, Sabouraud's dextrose broth medium plates were utilized and the same route as that for determination of antibacterial activity was employed and diameter of zone of inhibition was quantified after 48-72 hours. Fluconazole (1 mg/mL) was utilized as standard. The procedures for assaying activities were repeated in triplicates to validate the readings of diameter of zone of inhibition for each of the test strain. Additionally, minimum inhibitory and minimum lethal concentration were also determined by preparing nano-solution $(100 \mu \mathrm{L})$ in sterile DMSO and sequentially diluted with $\mathrm{N}$-saline $(0.85 \% \mathrm{NaCl})$ and similar amount of bacterial or fungal suspension was poured to different test-tubes and kept for $48 \mathrm{~h}$ incubation period.

\section{Spectroscopic characterization}

Elite-UV-Visible spectrophotometer, X'PERT-PRO Diffractometer, PanAlytical; CuK $\alpha$ radiation $\left(\lambda_{\max }=1.54 \AA\right)$, Transmission Electron Microscope (JEOL JEM 1011, 100kva) and FTIR Spectrophotometer Perkin Elmer Model RZX has been used to characterize $\mathrm{ZnO}$ nanoparticles.

\section{RESULTS AND DISCUSSION}

\section{Characterization}

The formation of $\mathrm{ZnO}$ nanoparticles was sensibly confirmed by UV-Vis spectrophotometer within the 250-700nm range. The Electronic absorption spectrum of biosynthesized $\mathrm{ZnO}$ nanoparticles represented a characteristic peak at 352nm Fig. 1. The calculated direct band gap (Eg) was $3.52 \mathrm{eV}$ and it was calculated by the following equation i.e.:

$$
\mathrm{Eg}=\frac{1240}{\lambda(\mathrm{eV})}
$$

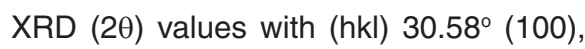
$33.22^{\circ}(002), 35.06^{\circ}(101), 46.38^{\circ}(102), 55.40^{\circ}$ (110) and $61.63^{\circ}(103)$ were observed and pattern displayed the formation of hexagonal phase $\mathrm{ZnO}$ nanostructures Figure 2.

TEM measurements confirmed that $\mathrm{ZnO}$ nanoparticles were nearly hexagonal in shape and nanoparticles size was found in the range of 16-38 $\mathrm{nm}$ having average diameter $27 \mathrm{~nm}$ Figure 3.

In FT-IR spectrum, a broad and overlapped peak is present between $3000-3550 \mathrm{~cm}^{-1}$ which is centered at $3394 \mathrm{~cm}^{-1}$ corresponding to $\mathrm{O}-\mathrm{H}$ stretching of hydroxyl group (intermolecular hydrogen bonded) along with other groups having exchangeable protons (amine, amide, carboxylic acid groups) are predictable. The absorptions at $1787.61 \mathrm{~cm}^{-1}$ and $1763.21 \mathrm{~cm}^{-1}$ were expected for $\mathrm{C}=\mathrm{O}$ stretching vibrations, peak at $1593 \mathrm{~cm}^{-1}$ indicates $\mathrm{N}-\mathrm{H}$ bending of amine, absorption peak at $1384 \mathrm{~cm}^{-1}$ is related with $\mathrm{O}-\mathrm{H}$ bending (alcohol, phenol and carboxylic acid groups), absorption at $1069 \mathrm{~cm}^{-1}$ is due to $\mathrm{C}-\mathrm{N}$ stretching (amine), absorptions at $902,886 \mathrm{~cm}^{-1}$ and $835 \mathrm{~cm}^{-1}$ are related with $-\mathrm{C}=\mathrm{C}$ - bending, absorption at $541 \mathrm{~cm}^{-1}$ is due to $\mathrm{Zn}-\mathrm{O}$ bending Figure 4 . 


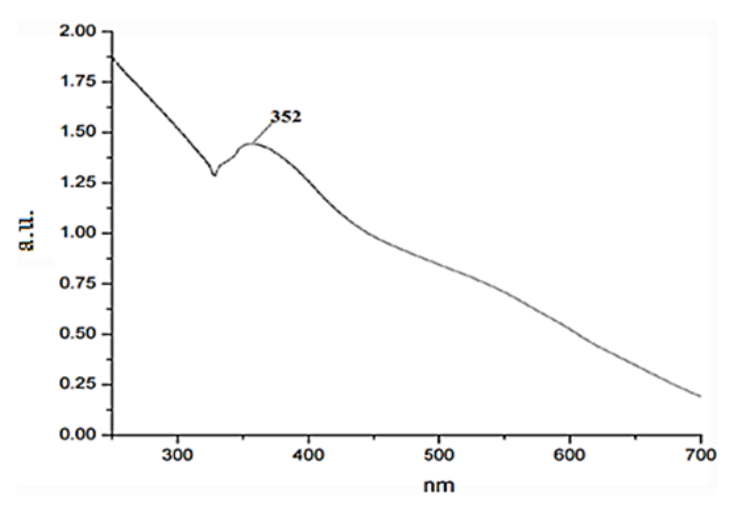

Fig. 1. UV-Vis spectrum of $\mathrm{ZnO}$ nanoparticles

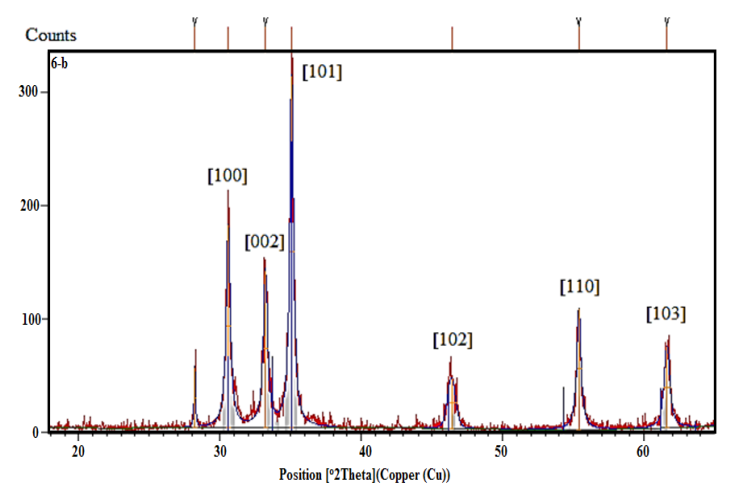

Fig. 2. XRD pattern of $\mathrm{ZnO}$ nanoparticles

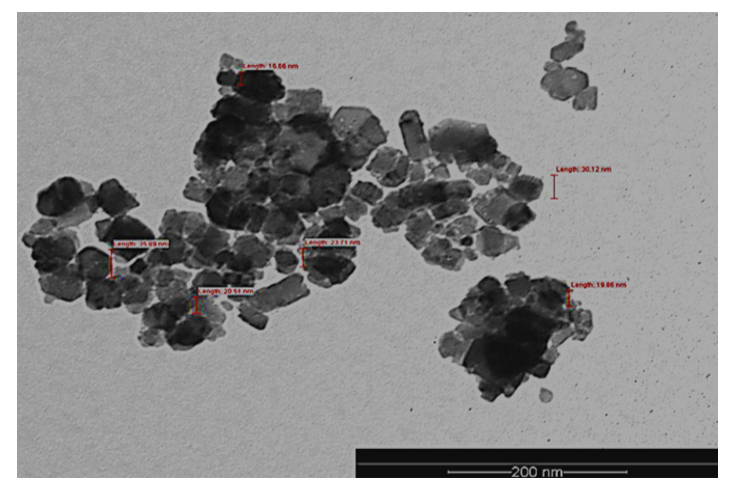

Fig. 3. TEM image of ZnO nanoparticles

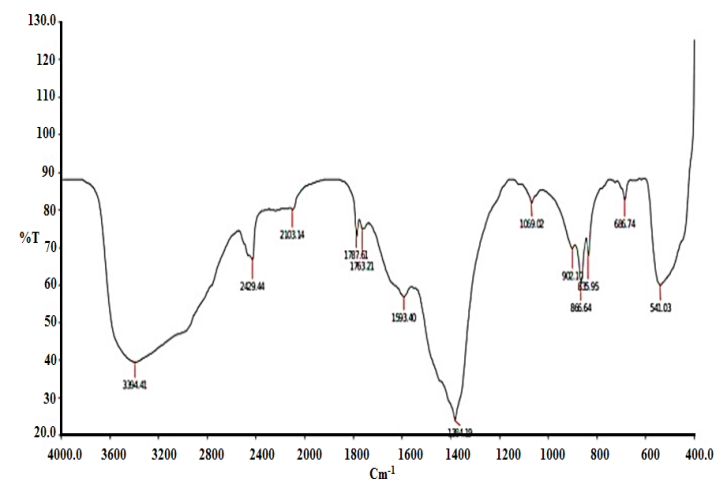

Fig. 4. FTIR spectrum of ZnO nanoparticles
From obtained results, C. acuminatus may be considered as a remarkable supply for the future nano-medicine and this property is supposed to be due to their active bio components that played an important role in the development of $\mathrm{ZnO}$ nanoparticles which is further supported by the fact that the plant extracts are very useful agents in the synthesis of metallic nanoparticle ${ }^{24}$. Based on the capability of plants to reduce metal ions and the participation of energetic bioreductants and stabilizers, the synthesis of $\mathrm{ZnO}$ nanoparticles could be expected. Various studies suggested that $\mathrm{ZnO}$ nanoparticles reveal a characteristic broad absorption peak in the 330-460 nm range ${ }^{25}$, peaking at $352 \mathrm{~nm}$ confirms the fabrication of $\mathrm{ZnO}$ nanoparticles using active bio components in the leaf extract. The existence of leaf extract bio-components such as flavonoids, and other polyphenols that remained around zinc ions even after repeated washing with water and ethanol, were indicated by different peaks present in the FTIR spectrum. These hydroxyl group bearing bio compounds assisted in the reduction of zinc ions to $\mathrm{ZnO}$ nanoparticles and could be accounted for their interaction with the zinc surface; forming a coating around the nanoparticles and preventing their further agglomeration ${ }^{26}$. The absorption in the UV region and its band gap implies its utility in the medical field due to catalytic action against microbial systems ${ }^{27}$. XRD diffraction pattern of the nanopowder revealed the formation of hexagonal phase $\mathrm{ZnO}$ nanostructures. Hexagonal structure of the synthesized $\mathrm{ZnO}$ nanoparticles was confirmed by the TEM images.

\section{Antimicrobial activity of ZnO Nps}

Metal based nanoparticles shows potential anti-microbial activity in comparison to their bulky forms, and it may be due to large surface area of nanoparticles ${ }^{28}$. Suresh D, et al.,2015 developed multifunctional $\mathrm{ZnO}$ nanoparticles using Cassia fistula extract and confirmed their potential antibacterial

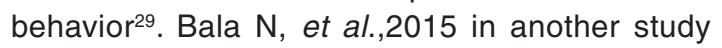
reported the $\mathrm{ZnO}$ nanoparticles through Hibiscus subdariffa extract and this study showed prominent antibacterial effects of synthesized nanoparticles ${ }^{30}$. Furthermore, in last few years, various researchers have confirmed boosted antimicrobial behavior of plant extract mediated synthesized metallic nanoparticles. In this research work, antibacterial and antifungal activities of $C$. acuminatus leaf extract mediated synthesized $\mathrm{ZnO}$ nanoparticles were 
investigated by using standard methods with some modifications. Antibacterial activity of $\mathrm{ZnO}$ sample was examined against $B$. subtilis, $S$. aureus and $P$. aeruginosa strains (Table 1). The nano-agents displayed beneficiary diameter of zone of inhibition against $B$. subtilis and $S$. aureus at $35 \mathrm{~mm}$ and $32 \mathrm{~mm}$, respectively and their MIC and MLC (Table 2) values further confirmed the biocidal effects on selected microbial pathogens.

Table 1: Antibacterial activity of ZnO Nps in terms of zone of inhibition $(\mathrm{mm})$

\begin{tabular}{cccc}
\hline \multirow{2}{*}{ Sample } & \multicolumn{3}{c}{ Diameter of zone of inhibition $(\mathrm{mm})$} \\
& P. aeruginosa & S.aureus & B.subtilis \\
\hline ZnO Nps $(100 \mu \mathrm{L})$ & 15 & 32 & 35 \\
Erythromycin & 45 & 35 & 38 \\
\hline
\end{tabular}

Table 2: Antibacterial activity of ZnO Nps in terms of MIC and MLC values $(\mu L)$

\begin{tabular}{cccccc}
\hline \multicolumn{2}{r}{$P$ aeruginosa } & \multicolumn{2}{c}{ S. aureus } & \multicolumn{2}{c}{ B. subtilis } \\
\hline MIC & MLC & MIC & MLC & MIC & MLC \\
5 & 10 & 22 & 28 & 5 & 10 \\
\hline
\end{tabular}

*MIC- Minimum inhibitory concentration and

MLC- Minimum lethal concentration

Jamdagni $P$, et al.(2018) in his study reported that using flower extract it is possible to develop active antifungal $\mathrm{ZnO}$ nano agents (Jamdagni 2018). In our case, antifungal activity of $\mathrm{ZnO}$ nanoparticles has been tested against C. albicans and S. cerevisiae and their diameter of zone of inhibition $(\mathrm{mm})$ were sensibly measured at $10 \mathrm{~mm}$ and $15 \mathrm{~mm}$, respectively (Table 3 ). Furthermore, the MIC and MLC values (Table 4) of nano samples showed their effectiveness against the selected fungal strains.

Table 3: Antifungal activity of ZnO Nps in terms of zone of inhibition $(\mathrm{mm})$

\begin{tabular}{|c|c|c|}
\hline \multirow[t]{2}{*}{ Sample } & \multicolumn{2}{|c|}{ Diameter of zone of inhibition ( $\mathrm{mm}$ ) } \\
\hline & C. albicans & S. cerevisiae \\
\hline ZnO Nps (100 $\mu \mathrm{L})$ & 10 & 15 \\
\hline Fluconazole & 28 & 27 \\
\hline
\end{tabular}

Table 4: Antifungal activity of $\mathrm{ZnO}$ Nps in terms of MIC and MLC $((\mu L)$

\begin{tabular}{lccc}
\hline \multicolumn{2}{c}{ C. albicans } & \multicolumn{2}{c}{ S. cerevisiae } \\
\hline MIC & MLC & MIC & MLC \\
03 & 07 & 06 & 10 \\
\hline
\end{tabular}

Thus from this section of antibacterial and antifungal activities, it's not surprising if we assume that nanoparticles with such antibacterial and antifungal potential against the selected strains may result benefits for the clinicians or experimenters on further investigating their action against other drug resistant pathogenic strains. This study may also motivate them for their large scale production.

\section{CONCLUSION}

The above research work provides a sustainable pathway for the fabrication of $\mathrm{ZnO}$ nanoparticles using aqueous leaf extract of C. acuminatus. This sustainable pathway helps in the useless destruction of the biodiversity as it demands a very small amount of the plant material and other supporting materials. The leaf extract of the $C$. acuminatus proved to be very efficient for the fabrication and stability of the zinc ions. The characterization part confirmed that the fabricated materials are in the nanometer range and encapsulated by bio components present in the leaf extract. Apart from this, evaluation of antimicrobial activity against selected microbes showed very good results. Such antimicrobial potential in synthesized ZnO nanoparticles might be due to pooled effect of biocidal property of zinc ions and C. acuminatus leaf metabolites. Therefore, antimicrobial results of synthesized $\mathrm{ZnO}$ nanoparticles seem motivating for the creation of other metal based nanoparticles through $C$. acuminatus extract for potential applications in various fields of science and technology.

\section{ACKNOWLEDGEMENT}

The authors acknowledged University Grant Commission for the financial assistance through the Junior Research Fellowship and NCFT, New Delhi for performing antimicrobial tests.

\section{Conflict of interest}

Contributing authors have no conflict of interest regarding the publication of this research work. 


\section{REFERENCES}

1. Geonmonond, R. S.; Silva A. G. D.; Camargo, P. H. An. Acad. Bras. Cienc., 2018, 90, 719-744.

2. Sobha, K.; Surendranath, K.; Meena, V.; Jwala, T. K.; Swetha, N.; Latha, K. S. M. Biotechnol. Mol. Biol. Rev. 2010, 5(1), 1-12.

3. Shah, R. K.; Boruah, F.; Parween, N. Int. J. Curr. Microbiol. Appl. Sci., 2015, 4(8), 444-450.

4. Poovizhi J.; Krishnaveni B. Int. J. Pharm. Sci. Drug. Res., 2015, 7(5), 25-431.

5. Shekhawat, M. S.; Ravindran, C. P.; Manokari M. Trop. Plant Res., 2014, 1(2) 48-59.

6. Fatimah, I.; Pradita, R. Y.; Nurfalinda, A. Procedia Eng., 2016, 148, 43-48.

7. Manokari, M.; Ravindran, C. P.; Shekhawat M. S. WSN., 2016, 30, 117-128.

8. Yuvakumar, R.; Suresh, J.; Hong, S. I. Adv. Mat. Res., 2014, 952, 137-140.

9. Jamdagni, P.; Khatri, P.; Rana, J. S. J. King Saud Univ. Sci., 2018, 30(2), 168-175.

10. Sharma, D.; Kanchi, S.; Bisetty, K. Arab. J. Chem., 2019, 12(8), 3576-3600.

11. Sangeetha, G.; Rajeshwaria, S.; Venckatesh, R. Mater. Res. Bullet., 2011, 46, 2560-2566.

12. Sawai, J. J. Microbiol. Methods., 2003, 54, 177-182.

13. Ahmed, S.; Annu,; Chaudhry, S. A.; Ikram, S. J. Photochem. Photobiol. B., 2017, 166, 272-284.

14. Yamamoto, O. Int. J. Inorg. Mater., 2001, 3, 643-646.

15. Hameed, A. S. H.; Karthikeyan, C.; Ahamed, A. P.; Thajuddin, N.; Alharbi, N. S.; Alharbi, S. A.; Ravi, G. Sci. Rep., 2016, 6(1), 1-11.

16. Smijs, T. G.; Pavel, S. Nanotechnol. Sci. Appl., 2011, 4, 95-112.

17. Sirelkhatim, A.; Mahmud, S.; Seeni, A.; Kaus, N. H. M.; Ann, L. C.; Bakhori, S. K. M.;
Mohamad, D. Nanomicro. Lett., 2015, 7(3), 219-242.

18. Gaur, R. D. Flora of the District Garhwal, North West Himalaya. Transmedia., 1999.

19. Kumar, G.; Badoni, P. P.; Singh, M. Int. J. Adv. Res. Sci. Eng. Technol., 2018, 7, 135-139.

20. Sati, S. C.; Sati, M.; Sharma, A.; Joshi, M. Int. J. Pharm. Pharm. Sci., 2010, 2, 58-60.

21. Perez, C.; Anesini, C. J. Ethnopharmacol., 1994, 44, 41-46.

22. Usman H.; Abdulrahman, F. I.; Ladan, A. H. Res. J. Biol. Sci., 2007, 2(3), 244-247.

23. Vollekova, A.; Kostalova, D.; Sochorova, R. Microbiology., 2001, 46(2), 107-111.

24. Makarov, V. V.; Love, A. J.; Sinitsyna, O. V.; Makarova, S. S.; Yaminsky, I. V.; Taliansky, M. E.; Kalinina, N. O. Acta Naturae., 2014, 6(1), 35-44.

25. Dobrucka, R.; Dlugaszewska, J.; Kaczmarek, M. Biomed. Microdevices., 2018, 20(1), 5-18.

26. Datta, A.; Patra, C.; Bharadwaj, H.; Kaur, S.; Dimri, N.; Khajuria, R. J. Biotechnol. Biomater., 2017, 7(3), 271-276.

27. Zhang, H.; Ji, Z.; Xia, T.; Meng, H.; Low-Kam, C.; Liu, R.; Pokhrel, S.; Lin, S.; Wang, X.; Liao, Y.P.; Wang, M. ACS Nano., 2012, 6(5), 4349-4368.

28. MubarakAli, D.; Thajuddin, N.; Jeganathan, K.; Gunasekaran, M. Colloids Surfaces B., 2011, 85, 360-365.

29. Suresh, D.; Nethravathi, P. C.; Rajanaika, H.; Nagabhushana, H.; Sharma, S. C. Mater Sci Semicond Process., 2015, 31, 446-454.

30. Bala, N.; Saha, S.; Chakraborty, M.; Maiti, M.; Das, S.; Basu, R.; Nandy, P. RSC Adv., 2015, 5, 4993-5003. 